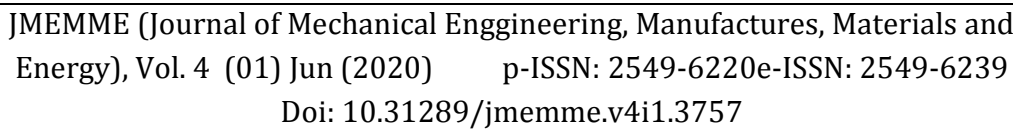

JMEMME (Journal of Mechanical Engineering, Manufactures, Materials and Energy)

\title{
Menentukan Predictive Maintenance Pada Kerusakan Turbocharger Diesel Engine
}

\section{Determine Predictive Maintenance of Diesel Engine Turbocharger Damage}

\author{
Wilarso*, Aswin Domodite, Hilman Sholih \\ Sekolah Tinggi Teknologi Muhammadiyah Cileungsi \\ Diterima: 08-05-2020 ; Disetujui: ; Diterbitkan: 30-06-2020 \\ *Corresponding author: wilarso@sttmcileungsi.ac.id
}

\begin{abstract}
Abstrak
Diesel Engine yang beroperasi pada salah satu pembangkit listrik di wilayah Sulawesi mengalami kerusakan pada turbocharger, indikasi sebelum kejadian unit trip/shutdown dan terindikasi di sistem Module Bearing Display Module (BDM) turbin dan kompresor disisi bank kiri, Module vibrasi display (VDM) pada bank kiri, modul vibrasi display axial bank kiri. Untuk mengidentifikasi kerusakan, operator melakukan pengecekan turbocharger pada bank kiri yang mengalami kerusakan dan setelah dilakukan pembongkaran komponen turbocharger ditemukan turbin wheel patah. Tujuan dalam penelitian ini menentukan akar penyebab kerusakan turbocharger agar kerusakan yang sama tidak terulang kembali. Adapun metode dalam penelitian ini adalah uji laboratorium komponen turbocharger yang patah. Dari kerusakan turbocharger bank kiri probability disebabkan oleh: 1) partikel valve, 2. Partikel bellow. Hasil dan Pembahasan kerusakan turbin wheel disebabkan vibrasi pada engine, yang mengakibatkan kerusakan pada wheel turbocharger. Vibrasi yang berasal dari sistem pembakaran yang tidak normal, dan menyebabkan pengelasan antara sliding plate dengan metal base pada bellows terlepas dan terdorong gas buang menuju turbocharger. Saran pengecekan secara berkala secara mengukur parameter vibrasi pada unit pembangkit.
\end{abstract}

Kata Kunci: Diesel Engine, Turbocharger, Blade Patah.

\begin{abstract}
The Diesel Engine operating in one of the power plants in the Sulawesi region suffered damage to the turbocharger, an indication before the trip / shutdown unit occurrence and indicated in the turbine Module Bearing Display Module (BDM) system on the left bank side, Vibration display module (VDM) on the bank left, left bank axial bank vibration module. To identify the damage, the operator checks the turbocharger on the left bank that is damaged and after disassembling the turbocharger component, the turbine wheel is broken.The purpose of this study is to determine the root cause of the turbocharger damage so that the same damage does not recur. The method in this research is a laboratory test for broken turbocharger components. From the left bank probability turbocharger damage is caused by: 1) valve particles, 2. Bellows particles. Results and Discussion Turbine wheel damage is caused by vibration on the engine, which results in damage to the turbocharger wheel. Vibration originating from the combustion system is not normal, and causes welding between the sliding plate and the metal base on the bellows to be released and the exhaust gas is pushed towards the turbocharger. Suggestions for checking periodically by measuring the vibration parameters on the generating unit.
\end{abstract}

Keywords: Diesel Engine, Turbocharger, Broken Blade 
JMEMME (Journal of Mechanical Enggineering, Manufactures, Materials and Energy), 4 (o1) (2020): 50-59

How to Cite: Wilarso, 2020, Menentukan Predictive Maintenance Pada Kerusakan Turbocharger Diesel Engine, JMEMME (Journal of Mechanical Enggineering, Manufactures, Materials and Energy), 4(01): 50-59 


\section{PENDAHULUAN}

Pembangkit listrik dengan total daya mampu 64 MW ini terdiri dari 6 unit generator set dengan kapasitas masingmasing mesin 11.3 MW. Untuk meningkatkan tenaga dan efisiensi, masing -masing mesin dilengkapi dengan dua unit turbocharger. Pada tanggal 20 September 2017 pada pukul 21.40 WITA telah terjadi "trip" atau gangguan pada generator set (G\#4) di salah satu pembangkit tenaga diesel, dimana spesifikasi mesin yang rusak adalah diesel engine 11.3 MW. Kronologis pada saat kejadian mesin mengalami gangguan jaringan yang dimulai dari signal alarm di ruang kontrol unit mengindikasikan kegagalan: 1) Pada module Bearing Display Module (BDM) Turbin dan kompresor pada turbocharger sisi bank, 2) Vibration Display Module (VDM) horisontal bank A. 3) Vibration Display Module (VDM) axial bank A.

Kemudian, operator unit yang bertugas melakukan pengecekan pada generator set yang terindikasi mengalami kerusakan dan setelah dilakukan pengecekan ditemukan adanya kerusakan pada turbocharger sisi bank A dengan indikasi sight glass sisi kompresor dan sisi turbine terlihat gelap dan mengembun, dimana pengembunan pada sight glass disebabkan oleh temperatur yang tinggi pada turbocharger. Sehingga diperlukan melakukan pengecekan lebih lanjut, perbaikan dan juga analisis terhadap penyebab kerusakan Genset G\#4 di turbocharger. Pada tanggal 17 Oktober 2017, melepas turbocharger bank A milik mesin diesel 11,3 MW mesin no. 04 telah mengalami kerusakan, dimana terdapat komponen-komponen turbocharger yang rusak, diantaranya, turbine blade, shaft, nozzle ring.

Perawatan prediktif berdasarkan data, analog maupun digital, yang tercatat dalam sistem, diolah sedemikian rupa untuk menentukan langkah perbaikan. Dalam pemeliharaan prediktif ini untuk meningkatkan kinerja generator set untuk meminimalkan kerusakan yang besar dan menurunkan biaya perbaikan. [1] [2]

Dalam pemeliharaan prediktif ini, juga bisa menentukan kapan pekerjaan tersebut akan dilakukan, apakah dalam waktu dekat atau waktu lama.[3]

Tujuan penelitian ini untuk mengetahui akar penyebab kerusakan blade turbocharger patah yang mengakibatkan generator set tidak bisa beroperasi.

\section{METODE}

Kerusakan turbocharger ini terjadi di PJB Sappa, Sulawesi, dan dalam penelitian kerusakan blade turbocharger menggunakan metode pengujian metalografi untuk mengetahui sifat logam dan panduannya berdasarkan struktur mikro dari permukaan.

Dalam metode penelitian materian ini dilakuakn pengujian kekerasan material menggunakan vickers, pengujian ini untuk mengetahui kekerasan logam yang sangat lunak dan kekerasan logam yang sangat keras, bagian bagian blade yang rusak atau tidak. Adapun beban yang dipergunakan dalam pengujian kekerasan ada 2 variasi $25+1500$ gr dengan interval 10 gr, yang digunakan untuk pengujian mikro, 
sedangkan $2+120 \mathrm{~kg}$, dengan interval 1 $\mathrm{kg}$, untuk pengujian makro.

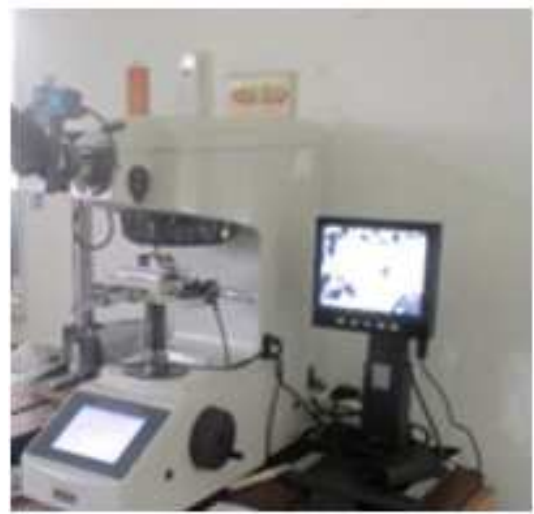

Gambar 1. Alat uji kekerasan material.

Untuk mengetahui komposisi kimia material blade menggunakan alat X Ray Fluorescence (XRF), adapun pengujian yang dilakukan menggunakan spektrometer, benda yang akan diuji, kemudian dipotong, dihaluskan dan diletakan pada tempat sampel, di spray pada permukaan material menggunakan argon. (Ar) Murni sampai 99,99\%.

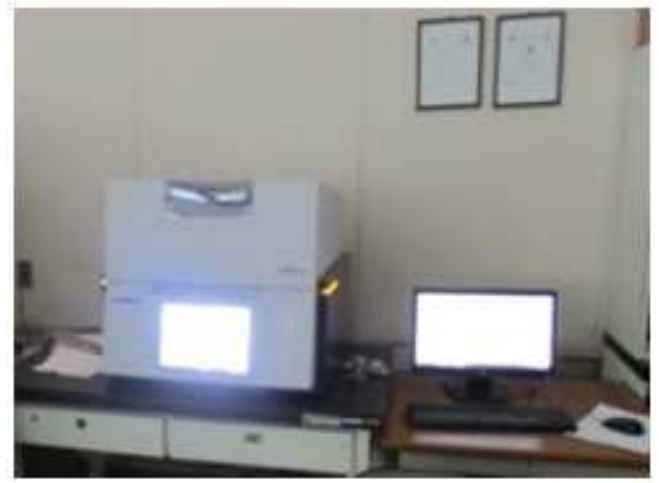

Gambar 2. Alat uji komposisi kimia

Dalam proses pelaksanaan penelitian untuk dapat menyelesaikan yang akan dicapai dari tujuan ini, langkah dimulai dari persiapan material atau bahan blade pada turbocharger yang menjadi penyebab terjadinya kerusakan pada turbocharger generator set 11,3 MW. Pada gambar 3 alur penelitian dalam menentukan akan penyebab patahnya turbin blade yang dilakukan,

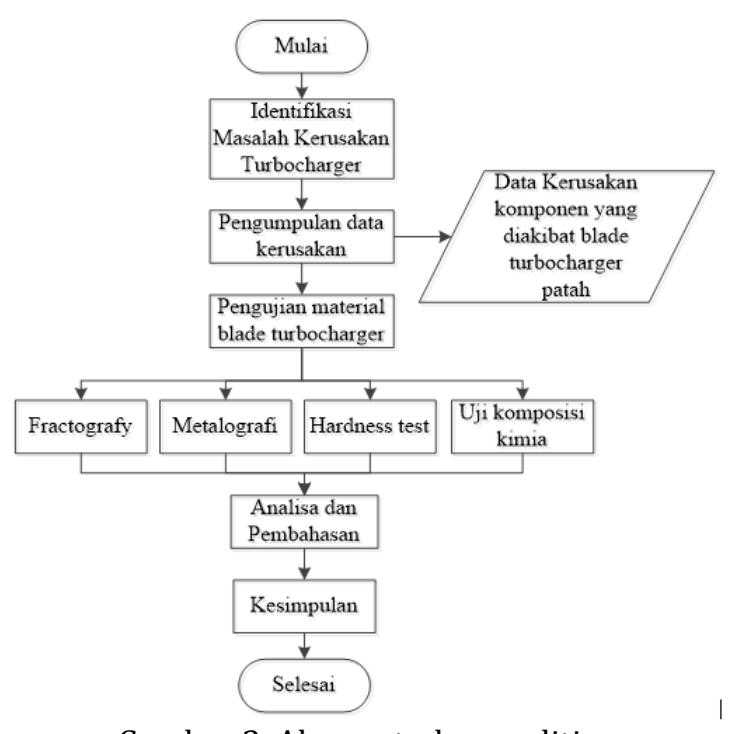

Gambar 3. Alur metode penelitian

\section{HASIL DAN PEMBAHASAN}

Pada analisis ini kerusakan pada blade turbocharger, dimana komponen blade turbocharger patah. Patahnya blade tidak beroperasikan unit pembangkit di PLTD dan tidak bisa suplai daya yang dibutuhkan oleh PLN, yang dijelaskan pada gambar 4 .

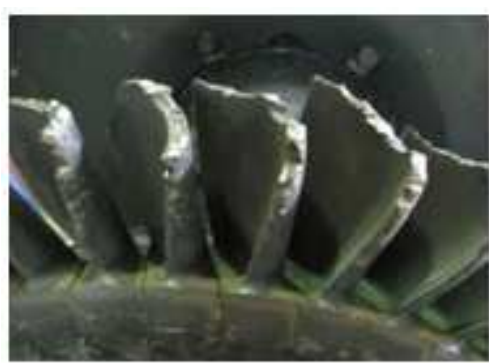

Gambar 4. Blade yang rusak pada turbine

Dan gambar 5, below exhaust manifold, terlepas, dan material ini mengarah dan berbenturan ke turbocharger, dan mengakibatkan patahnya blade turbocharger, dan merusak komponen nozzle ring, shaft, housing turbocharger. 


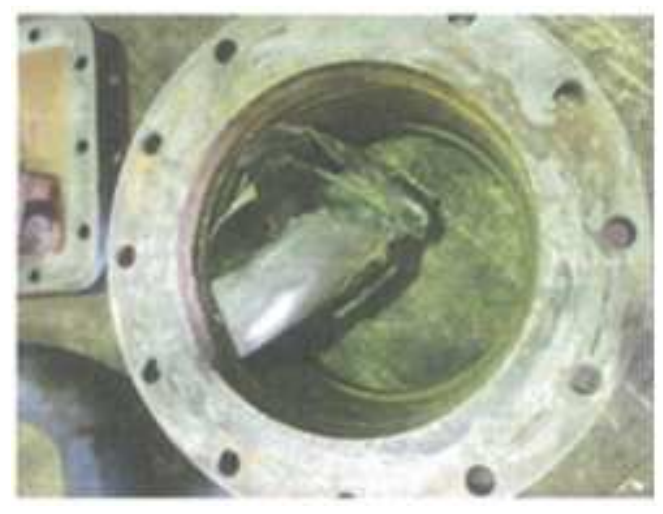

Gambar 5. Below

Dalam fishbone analysis (Gambar 6) [4] ada 4 komponen yang menjadi perhatian dalam penelitian ini, 1) material: pada material turbocharger tidak ada keterkaitan dengan kerusakan, didalam material jika terjadi kegagalan manufaktur, seperti: inklusi atau nik, akan mengakibatkan kerusakan yang besar. 2) machine: ada 2 poin yang menjadi perhatian dalam kerusakan turbocharger, diantaranya manusia unbalance dan vibrasi [5] [11]. 3) man: tenaga kerja sudah maksimal dalam memonitoring dalam pengoperasian unit. 4) metode perawatan tidak maksimal. Pemeliharaan hanya di bagian turbocharger.

Setelah dilakukan analisis penyebab kerusakan pada turbocharger dengan metode fishbone analysis [4], maka dapat disimpulkan penyebab utama dari kerusakan pada turbocharger.

1. Kerusakan pada turbocharger yang disebabkan karena eksternal material yang mengakibatkan blade wheel turbocharger patah dan merusak bagian-bagian lainnya di dalam turbocharger (Domestic Object Damage).
2. Material dari luar atau disebut dengan Foreign Object Damage (FOD) yang masuk kedalam sistem turbocharger dan merusak turbocharger

3. Perawatan (maintenance) yang tidak baik pada turbocharger.

A. Analisis Domestic Object Damaged (DOD)

Dari penemuan di lapangan, bahwasanya komponen pada turbine wheel mengalami kerusakan yaitu disisi ujung blade, untuk memastikannya perlu dilakukan pengujian pada material blade, untuk menentukan apakah material sudah mengalami kelelahan (fatigue), wear and tear, crack [6]. Gambar 7 pengecekan secara visual nozzle ring mengalami kerusakan pada bagian sudu, nozzle ring ini sebagai akibat patahnya blade turbocharger.

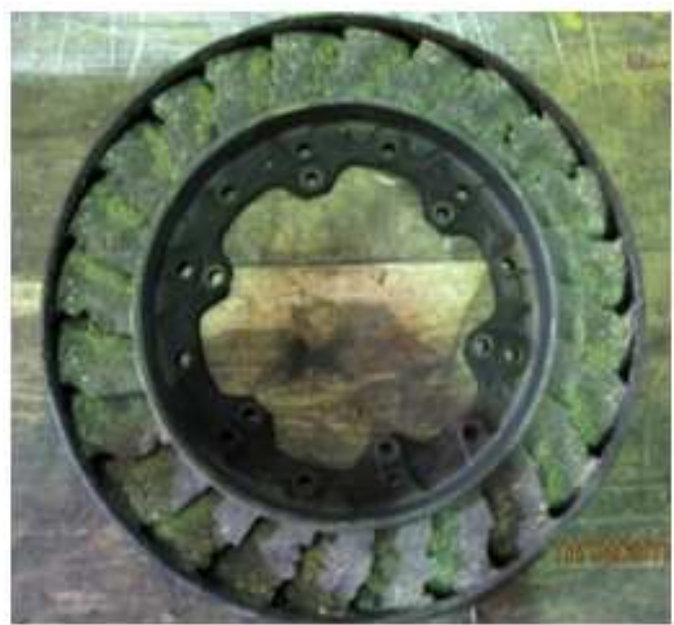

Gambar 7. Nozzle ring

Shaft pada turbocharger yang dijelaskan pada gambar 8, terindikasi scratches. 


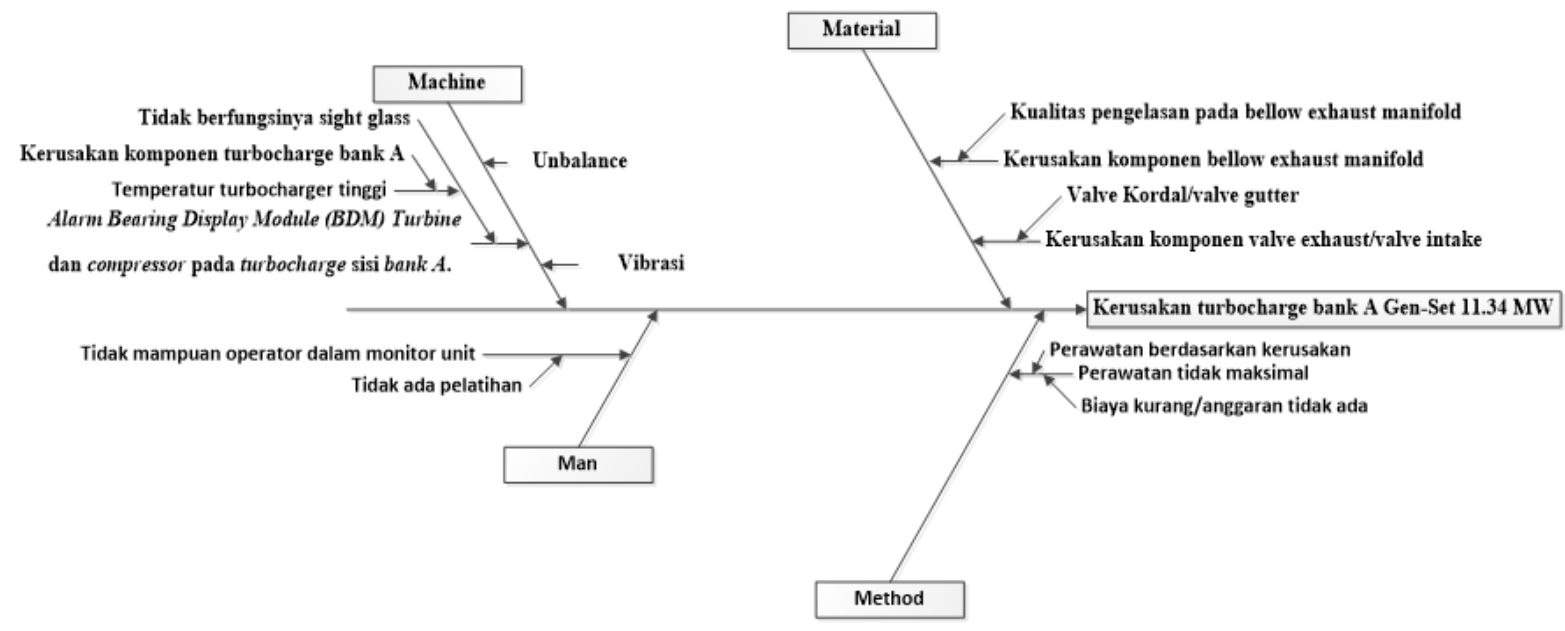

Gambar 6. Fishbone analysis

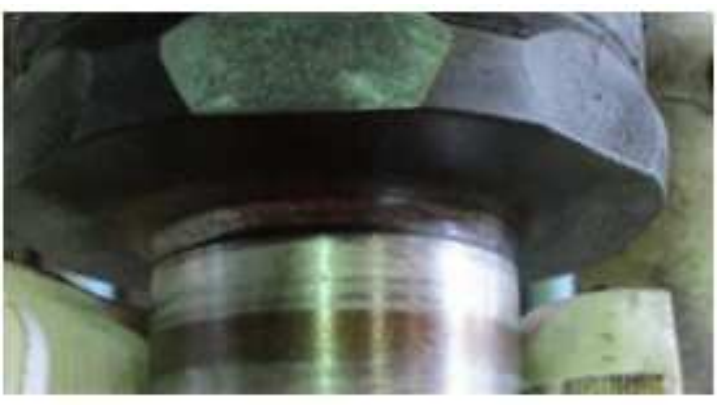

Gambar 8. Shaft pada turbocharger scratches

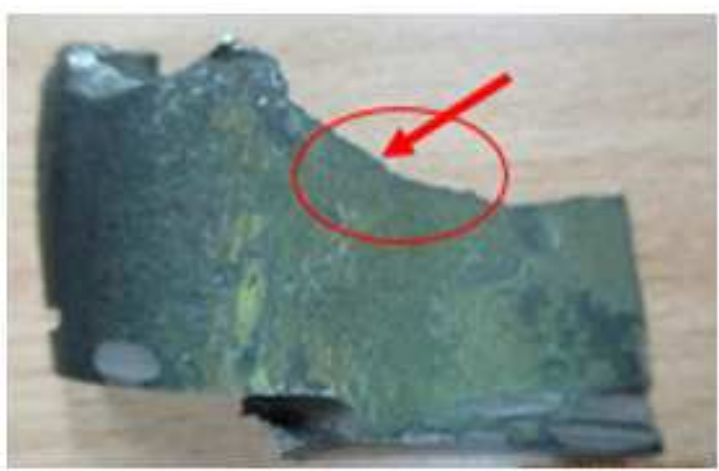

Gambar 9. Blade yang patah

B. Analisa material turbine wheel

Analisa ini dengan mengambil sampel pada material turbine wheel, yaitu dengan cara memotong beberapa bagian blade-nya setelah dilakukan pembongkaran. Untuk pengujian material blade ini, kami menggunakan metode-metode yang dipakai, antara lain: pengujian komposisi kimia, pengujian kekerasan, pengujian metallography. Dan pengujian fractography. Pengujian ini dilakukan di Laboratorium LIPI PUSLIT Metalurgi dan Material - Puspitek Serpong.

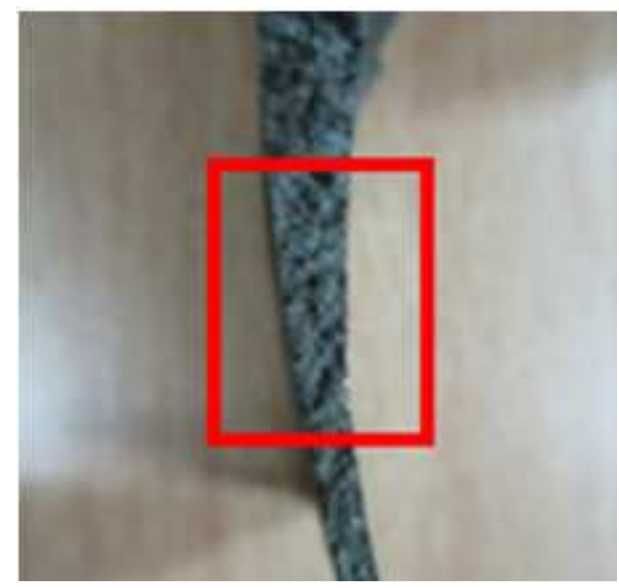

Gambar 10. Spesimen material turbine blade

\section{Hasil Pengujian Komposisi Kimia}

Analisa pengujian komposisi kimia [7] pada material turbine blade tersebut dilakukan dengan menggunakan X Ray Fluorescence (XRF) yaitu untuk mengetahui komposisi kimia yang terkandung pada material turbine blade, 
sehingga dari hasil pengujian tersebut dapat memberikan gambaran apakah jenis material tersebut.

Dari hasil pengujian komposisi kimia dapat dilihat bahwasanya material turbine blade adalah berjenis "nickelbase superalloys" [8] dan mendekati spesifikasi dari material Inconel 600, memiliki kemampuan untuk mempertahankan kekuatannya pada temperatur tinggi ( $>650$ oC). Kombinasi yang baik antara kekuatan tinggi dan keuletan yang baik pada temperatur rendah serta stabilitas permukaan yang baik, stabilitas permukaan yang berarti tahan korosi seperti penggunaan pada turbine blade di turbocharger.

Tabel 1. Hasil pengujian komposisi kimia

\begin{tabular}{|c|c|c|c|}
\hline No & $\begin{array}{c}\text { Wear } \\
\text { Element }\end{array}$ & $\begin{array}{c}\text { Hasil Uji } \\
\%\end{array}$ & Inconel $600(\%)$ \\
\hline 1 & $\mathrm{Ti}$ & 0.487 & \\
\hline 2 & Mo & 3.237 & \\
\hline 3 & $\mathrm{Mg}$ & 0.043 & 1.00 Max \\
\hline 4 & $\mathrm{Al}$ & 4.020 & \\
\hline 5 & $\mathrm{Si}$ & 0.275 & Max 0.5 \\
\hline 6 & $P$ & 0.002 & \\
\hline 7 & $\mathrm{Ca}$ & 0.127 & \\
\hline 8 & $\mathrm{Cr}$ & 9.241 & $14-17$ \\
\hline 9 & $\mathrm{Mn}$ & 0.004 & 1.00 Max \\
\hline 10 & $\mathrm{Fe}$ & 0.055 & 0.06 \\
\hline 11 & Co & 9.807 & $\min .72(\mathrm{Ni}+\mathrm{Co})$ \\
\hline 12 & Sc & 0.095 & \\
\hline 13 & $\mathrm{Ni}$ & 68.19 & $\min .72(\mathrm{Ni}+\mathrm{Co})$ \\
\hline
\end{tabular}

D. Hasil Pengujian Kekerasan

Pengujian kekerasan material turbine blade dengan metode Vicker, dimana dilakukan pemotongan material turbine blade untuk dibuatkan spesimen dan diambil di beberapa titik pengujian. Untuk hasil dari pengujian kekerasan material turbine blade ada di lampiran belakang. Hasil hardness test pada material blade turbocharger ini kekerasannya masih dinilai rata-rata 400 HV.

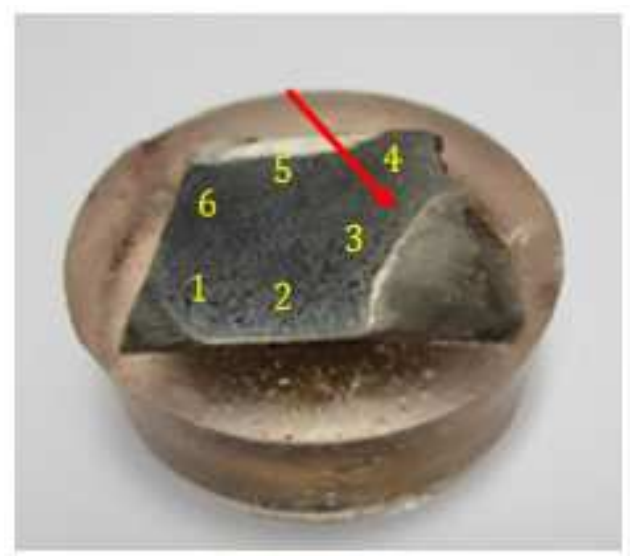

Gambar 11. Specimen material turbine blade

Adapun hasil pengujian terhadap material blade didapat sesuai table 2 .

Tabel 2. Pengujian kekerasan material

\begin{tabular}{|c|c|c|}
\hline $\begin{array}{c}\text { Posisi } \\
\text { pengujian }\end{array}$ & $\begin{array}{c}\text { Menggunakan } \\
\text { HVN }\end{array}$ & $\begin{array}{c}\text { Menggunakan } \\
\text { HRc }\end{array}$ \\
\hline 1 & 416.3 & 42.4 \\
\hline 2 & 403.1 & 41.1 \\
\hline 3 & 410.5 & 41.9 \\
\hline 4 & 392.1 & 40.0 \\
\hline 5 & 406.2 & 41.4 \\
\hline 6 & 402.4 & 41.0 \\
\hline Rata-Rata & 405.1 & 41.3 \\
\hline
\end{tabular}

\section{E. Hasil Pengujian Metallography}

Pengujian metallography dilakukan untuk menentukan mikrostruktur turbine blade setelah terjadinya kerusakan. Berikut adalah hasil 
mikrostruktur dari material turbine blade dengan pembesaran $100 x$, dalam mikrostruktur tersebut tidak ada indikasi inklusi maupun fatigue.

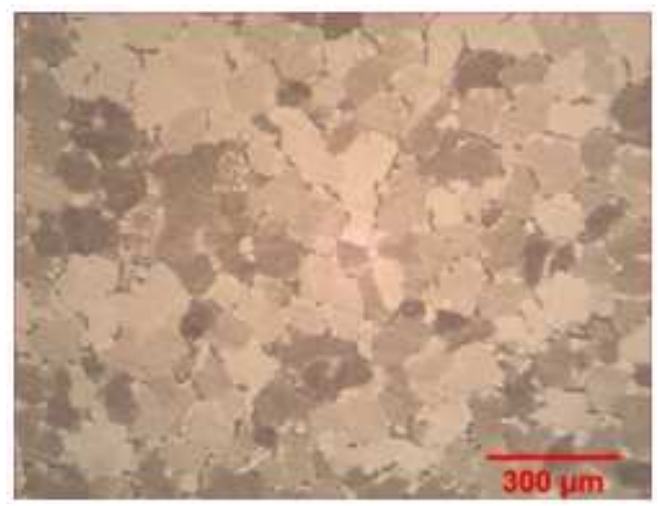

Gambar 12. Optical image 100x turbine blade material

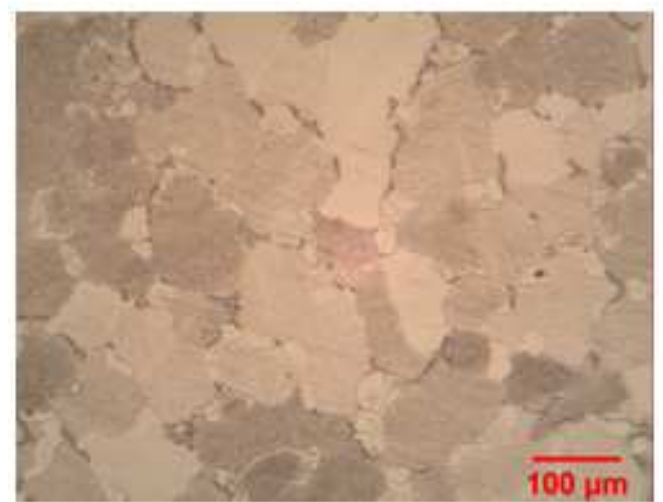

Gambar 13. Optical image 500x turbine blade

Dari analisa pada gambar 7 setelah dilakukan pengujian terhadap material blade yang rusak tidak ditemukannya ciri-ciri patahan fatigue, dan tidak adanya "benchmark", sehingga disimpulkan adanya fatigue loading.

Dari factrography yang terlihat adanya patah getas (brittle fracture), transgranular dan intergranular fracture yang disebabkan karena adanya impact overload dari material luar, sehingga dapat disimpulkan kerusakan pada material turbine blade adalah modus kerusakan patah secara tiba-tiba (suddenly) yang disebabkan impact overload.

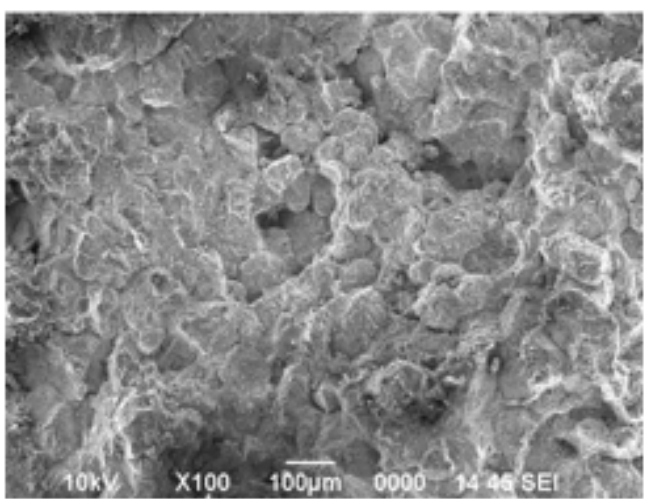

Gambar 14. Factrography dengan pembesaran 100x

Dari pengujian turbine blade yang patah dikarenakan benturan dengan logam yang berasal dari internal sistem pemasukan dan pembuangan gas buang, adapun material yang benturan dengan blade berasal dari below exhaust manifold. Belows ini sambungan antara elbow manifold dari cylinder head yang membuang gas buang dari hasil pembakaran.

Penyebab dari kegagalan pengelasan antara sliding plate dengan metal base pada below. Kondisi welding atau pengelasan pada sliding plate dengan metal base terlepas secara merata dan melingkar atau tidak terjadi fusion pada pengelasan. Tidak ditemukan indikasi keretakan (crack) [9] pada metal base ataupun sliding plate.

Untuk meminimalkan kerusakan turbocharger, langkah yang harus dilakukan predictive maintenance [10], dimana pemasangan sensor detonasi di area exhaust manifold pada generator set agar memaksimalkan fungsi kerja serta pengecekan secara berkala/preventive maintenance, untuk mengetahui lebih dini terhadap indikasi 
kerusakan, agar tidak menimbulkan biaya terlalu besar dalam hal perbaikan.

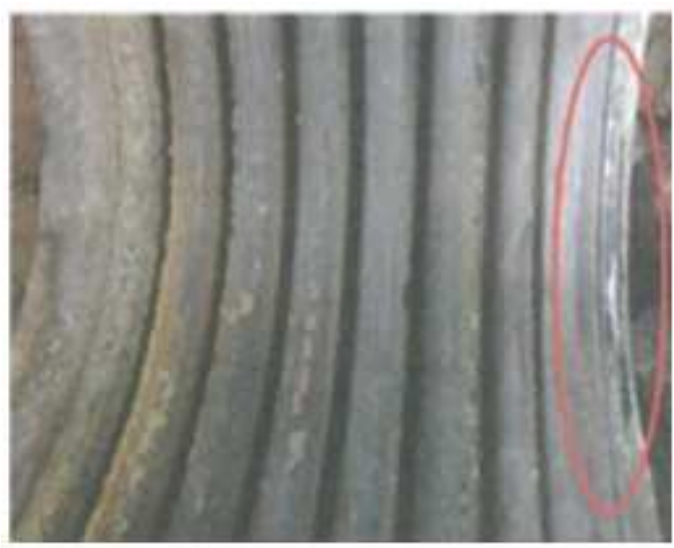

Gambar 15. Bentuk kegagalan welding pada metal base dan sliding plate

\section{KESIMPULAN}

Kerusakan turbocharger yang mengakibatkan tidak beroperasinya unit pembangkit dan penurunan suplai daya ke masyarakat, dari hasil analisis kerusakan dan berdasarkan hasil pengujian pada material turbine blade adalah kerusakan turbocharger dikarenakan benturan logam dengan logam, adapun logam berasal dari bellows exhaust manifold. Penyebab dari kegagalan pengelasan antara sliding plate dengan metal base pada bellows. Kondisi welding atau pengelasan pada sliding plate dengan metal base adalah terlepas secara merata dan melingkar atau tidak terjadi fusion pada pengelasan. Terlepasnya material bellow exhaust manifold ini disebabkan oleh getaran pada engine yang tinggi. Adapun getaran ini disebabkan oleh abnormality pada sistem pembakaran. Implementasi Pemeliharaan Prediktif dengan menggunakan spesial tool, recording dan analisis untuk mengetahui gejala kerusakan pada suatu peralatan, agar mengetahui indikasi-indikasi kerusakan, dan menurunkan biaya perbaikan. Untuk analisa selanjutnya bisa dilakukan pengujian vibrasi pada generator set dengan kapasitas 11.3 MW. Dalam penelitian ini dapat dikembangkan lagi mengenai detonasi pada sistem pembakaran diesel engine dengan bahan bakar solar.

\section{PENGHARGAAN}

Kami ucapakan banyak terima kasih kepada semua pihak yang membantu dalam penelitian ini.

\section{REFERENCES}

[1] N. Amruthnath and T. Gupta, "Fault Diagnosis Using Clustering. What Statistical Test to use for Hypothesis Testing?," Mach. Learn. Appl. An Int. J., vol. 6, no. 1, pp. 1733, 2019.

[2] N. Amruthnath, "Predictive maintenance-Fault Detection Predictive maintenance - Fault Detection," no. February, 2019.

[3] M. Brahimi, K. Medjaher, M. Leouatni, and N. Zerhouni, "Development of a prognostics and health management system for the railway infrastructure - Review and methodology," Proc. 2016 Progn. Syst. Heal. Manag. Conf. PHMChengdu 2016, vol. 2016, no. October, 2017.

[4] G. S. M. Mithun Ekanathan, Binu C. Yeldose, Prakash M. Kallanickal, "Root Cause Analysis to Identify the Problem Causing Turbine Failure," vol. 2, no. 2, pp. 527-535, 2013. 
[5] N. Wirth and A. Oeckerath, "Analysis of flow-induced vibrations in turbomachinery by mapping of complex fluid pressures," Int. J. Multiphys., vol. 9, no. 2, pp. 195-207, 2015.

[6] L. 0. A. Affonso, "Turbomachinery Blades," Mach. Fail. Anal. Handb., pp. 253-267, 2006.

[7] E. S. Al-hassani, "Investigation of Microstructure and Chemical Analysis Along Weldments AISI 410 MSS/ER Nicrmo-3," Eng. Technol. J., vol. 36, no. 5A, 2018.

[8] E. Akca and A. Gürsel, "A Review on Superalloys and IN718 NickelBased INCONEL Superalloy," Period. Eng. Nat. Sci., vol. 3, no. 1, 2015.

[9] B. Engels, "Lifetime prediction for Turbocharger Compressor Wheels - Why Use Titanium?," p. 13.

[10] V. F. A. Meyer, "Challenges and Reliability of Predictive Maintenance," no. March, p. 16, 2019.

[11] L. K. Bhagi, P. Gupta, and V. Rastogi, "A Brief Review on Failure of Turbine Blades," Proc. STME-2013 Smart Technol. Mech. Eng., no. October, pp. 1-8, 2013. 